\title{
OBSERVATIONS ON THE GROWTH OF THE ADOLESCENT ȘPINE
}

\author{
A. G. VELDHUIZEN, P. BAAS, P. J. WEBB
}

From the Royal National Orthopaedic Hospital, London, and the University of Groningen, The Netherlands

We have measured the increase in height and width of the vertebral bodies and expressed them as percentages of the total growth in children aged 10 to 17 years. The first group, 10 boys and 10 girls, each had a single thoracic adolescent idiopathic scoliosis while the second group, 10 girls, each had a single lumbar adolescent idiopathic scoliosis.

No significant differences were found between the growth increments and spinal dimensions of the vertebral bodies involved in the scoliotic curve and those vertebrae outside the curve in the same patient. The vertebrae were more slender in girls than in boys.

For over 100 years the association between idiopathic scoliosis and vertebral growth has been discussed by various authorities (Duthie 1959; Duval-Beaupere et al. 1970). Some have maintained that the development of the deformity has been limited to the growth period in general, while others have stressed its relationship more particularly to periods of rapid growth (Willner 1972). Mild to moderate curves, with a Cobb angle of less than $60^{\circ}$, usually progress little after completion of spinal growth (Collis and Ponseti 1969).

Recent renewed interest in growth disturbance as an explanation for the deformity seen in adolescent idiopathic scoliosis stimulated us to undertake this study (Dickson et al. 1984). As normal individuals do not have spinal radiographs taken at regular intervals, our objective was to determine the incremental growth of normal vertebral bodies during the period of rapid growth.

The only longitudinal study of the growth of normal Caucasian children was undertaken by Dr Harold Stuart, a paediatrician in Boston in the mid-1930s. Each of the children in his study was enrolled at birth and examined every three months during the first year and then annually. Each evaluation included an anthropometric assessment and a physical examination. Until the

A.G. Veldhuizen, MD, Orthopaedic Surgeon

P. Baas, Medical Student

Department of Orthopaedic Surgery, University Hospital, PO Box 30.001, 9700 RB Groningen, The Netherlands.

P.J. Webb, FRCS, Consultant Orthopaedic Surgeon

Royal National Orthopaedic Hospital, Brockley Hill, Stanmore, Middlesex HA7 4LP. England.

Requests for reprints should be sent to Dr A.G. Veldhuizen

(C) 1986 British Editorial Society of Bone and Joint Surgery $0301-620 \mathrm{X} / 86 / 5144 \$ 2.00$ potential hazards of repeated radiographs were recognised, these individuals had a spinal radiograph taken at each visit. At a scoliosis conference in 1979 Nehme, Riseborough and Reed presented data for normal spinal growth in children aged between 4 and 11 years, based on measurements from the full-length lateral spinal radiographs taken by Dr Stuart. Unfortunately no data was available for the later, more interesting period of growth to 17 years of age.

In order to establish some normal values for spinal growth, we have used full-length radiographs of patients with idiopathic scoliosis and measured the vertebral bodies in the normal parts of their spines. We assumed that the incremental growth might be different within the abnormal scoliotic segment, but not above or below the curve. We also measured growth increments within the deformed segment, and have compared our results with those reported in the literature.

\section{MATERIAL AND METHODS}

On the basis of the age of the patients and the type of scoliosis, we selected the radiographs of 30 Caucasian children who had been under observation for adolescent idiopathic scoliosis at the Royal National Orthopaedic Hospital in London.

The first group of 20 children ( 10 boys and 10 girls) had a single thoracic adolescent idiopathic scoliosis between T5-6 and T11-12. The second group of 10 children (all girls) had a single lumbar idiopathic scoliosis between L1-2 and L5. Standard full-length anteroposterior radiographs of each child's spine were available between the ages of 10 and 17 years. The average Cobb angle in both groups was $25.3^{\circ}$. The age and the standing height for each patient were recorded at the time each spinal radiograph was made. 
Diagonals are drawn from the easily recognisable corner points: they cross at the centre point. Lines $A C$ and $B D$ bisect the angles and are measured. This method is shown to determine the maximum height.
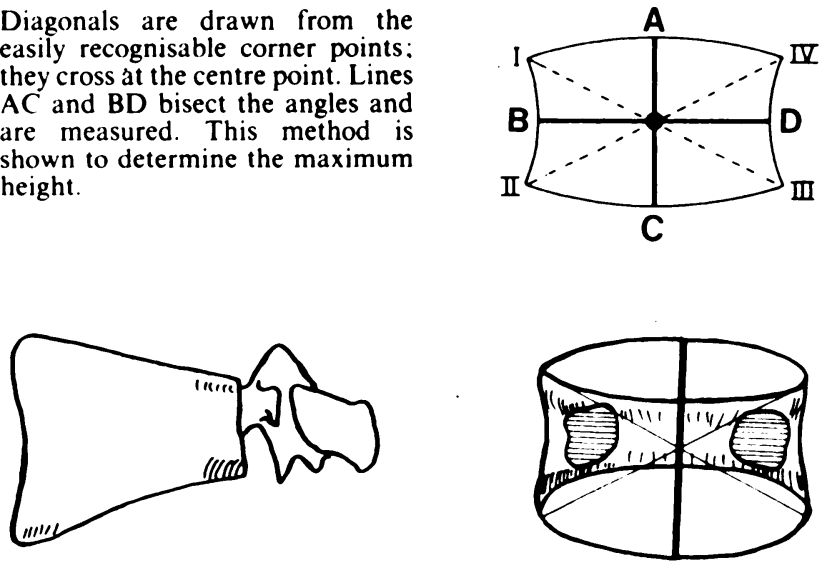

Fig. 1

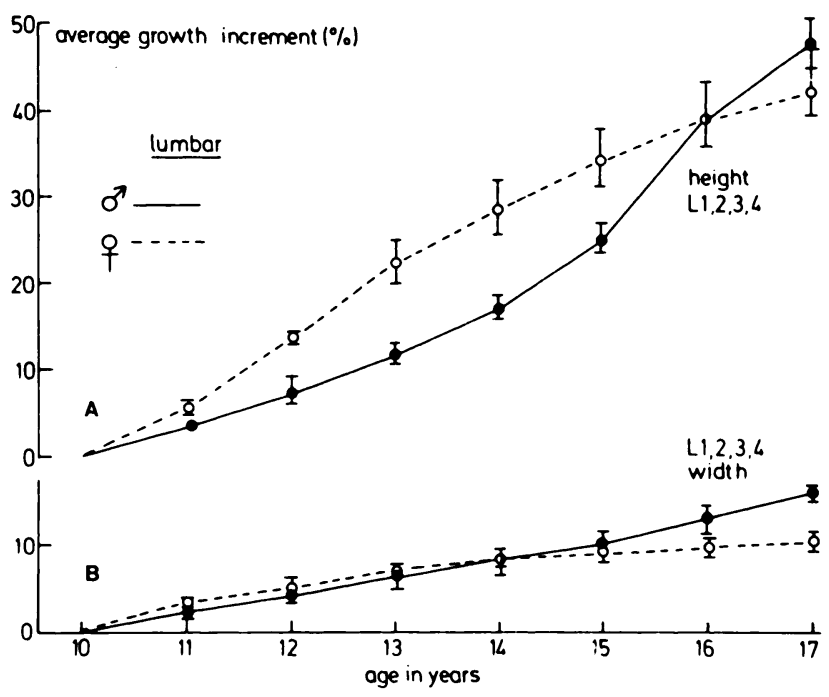

Fig. 2

Average growth increments in height (A) and in width (B) of the lumbar (normal) vertebrae for the first series.
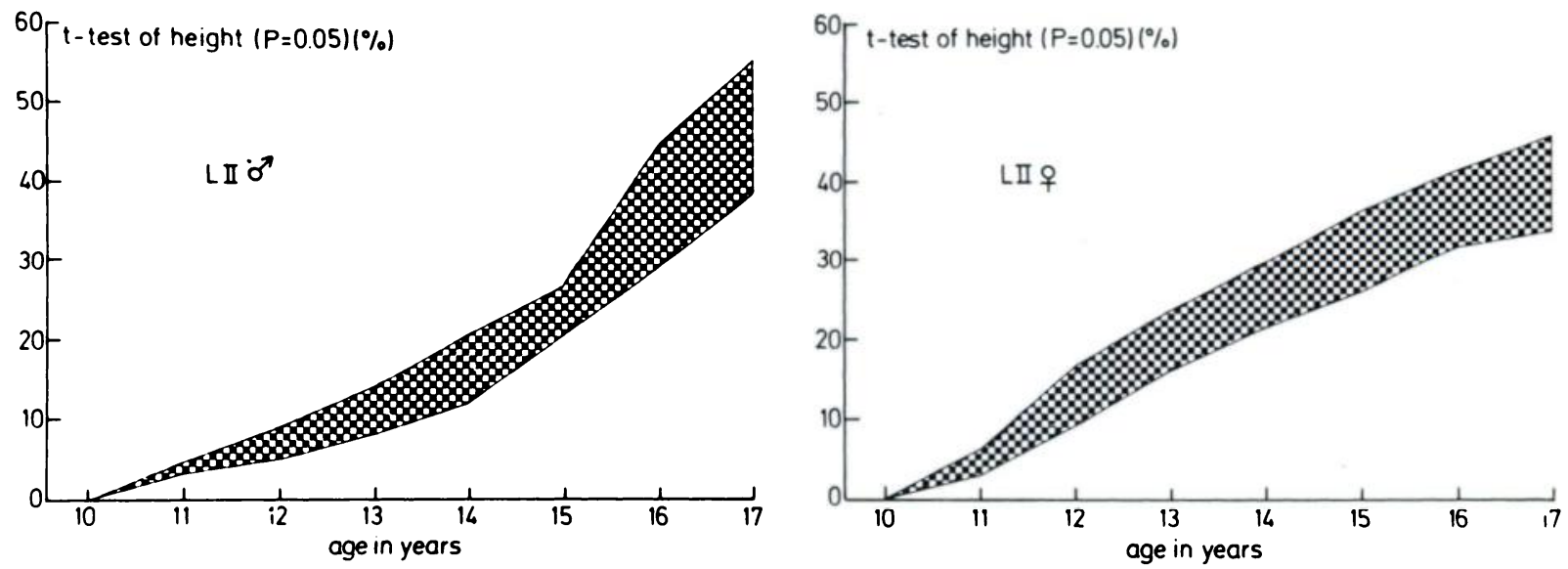

Fig. 3
Radiography was performed with the child in a standard upright position using a film-to-focus distance of $180 \mathrm{~cm}$ and the same radiographic equipment throughout the survey. Measurements of vertebral height and width were made directly on the radiograph using a sliding millimetre scale to an accuracy of $0.25 \mathrm{~mm}$ (Fig. 1). Vertebrae were selected for measurement only if their image showed minimal axial rotation because rotation makes impossible the accurate placement of comparable points on adjacent vertebrae. We measured the dimensions of the vertebral bodies of $\mathrm{T} 6, \mathrm{~T} 7, \mathrm{~T} 8, \mathrm{~T} 11$ and $\mathrm{L} 1$ to $\mathrm{L} 5$ in both groups of children.

Magnification error was assessed by using the same technique for seven additional patients with similar adolescent scoliosis with the addition of a $30 \mathrm{~cm}$ radioopaque ruler taped along the length of the patient's back. From this it was possible to calculate the magnification factor according to calender age for each vertebral body which was measured. The magnification error was minimal; only $0.16 \%$ and $0.25 \%$ for T6 and L4, respectively. The results reported for the main study have been adjusted for magnification.

\section{RESULTS}

Normal vertebrae. In the first group of 20 children the lumbar vertebral bodies were not involved in the scoliotic curve. These vertebrae showed a period of disproportionate increase in height which took place about two years earlier in girls than in boys (Fig. 2), starting in girls at about the age of 11 years and in boys at about 13 years. At the age of 17 years there was somewhat more longitudinal growth in boys than in girls, whose growth was nearly complete. Figure 3 shows, for L2 vertebra alone, separately for boys and girls, curves of percentage increase in height. The tinted areas indicate the range at each age, calculated at $p=0.05$ by Student's 
Table I. Normal lumbar vertebrae (first series)

\begin{tabular}{|c|c|c|c|c|c|c|c|c|c|}
\hline \multicolumn{5}{|c|}{ BOYS } & \multicolumn{5}{|c|}{ GIRLS } \\
\hline & \multicolumn{2}{|c|}{ Height $(m m)$} & \multicolumn{2}{|c|}{ Width $(\mathrm{mm})$} & & \multicolumn{2}{|c|}{ Height $(\mathrm{mm})$} & \multicolumn{2}{|c|}{ Width $(\mathrm{mm})$} \\
\hline & 10 years & 17 years & 10 years & 17 years & & 10 years & 17 years & 10 years & 17 years \\
\hline $\mathbf{L} \mathbf{1}$ & 19.5 & 28.2 & 35.0 & 40.1 & L1 & 19.7 & 27.8 & 33.4 & 37.2 \\
\hline L2 & 19.7 & 29.0 & 36.1 & 42.1 & L2 & 20.3 & 28.3 & 33.9 & 37.4 \\
\hline $\mathbf{L} 3$ & 19.7 & 29.6 & 38.0 & 44.4 & L3 & 20.6 & 30.2 & 35.6 & 39.1 \\
\hline L4 & 19.3 & 28.7 & 40.7 & 47.0 & L4 & 20.2 & 28.1 & 37.6 & 41.0 \\
\hline
\end{tabular}

Table II. Normal thoracic vertebrae (second series)

\begin{tabular}{lll}
\hline \multicolumn{3}{l}{ GIRLS } \\
\hline \multicolumn{3}{l}{ Height $(\mathrm{mm})$} \\
\cline { 2 - 3 } & 10 years & 17 years \\
\hline T6 & 13.9 & 19.4 \\
T7 & 14.2 & 19.3 \\
T8 & 14.9 & 19.2 \\
T11 & 18.8 & 26.9 \\
\hline
\end{tabular}

t-test. Furthermore, growth patterns were different within the lumbar spine: in boys L3 and L4 both increased in height and in girls this only occurred in the L3 vertebra. The increase in width in both boys and girls was much more gradual than the growth in height (Fig. 2). As shown in Table I, girls of 10 years of age had taller and narrower vertebrae than boys, while at the age of 17 years the width of the lumbar vertebrae was about $5 \%$ greater in boys than in girls.

The thoracic vertebrae in the second group of girls, again outside the scoliotic segment, showed smaller growth increments than the lumbar vertebrae in the girls in the first group (Fig. 4; Table II). As shown in Figure 5A, T7 and T8 vertebrae showed less longitudinal growth than $\mathrm{T} 6$ and $\mathrm{T} 11$.

Scoliotic vertebrae. The incremental growth of vertebral bodies within the deformed segment was also measured, in the thoracic spine in the first group and in the lumbar spine in the second group. The growth of the lumbar vertebrae in the second group (Fig. 6, Table III) did not differ greatly from those of the first normal group (Fig. 2, Table I). If anything, the height and width of the scoliotic vertebrae were slightly larger than those of the comparable normal vertebrae in the first group, but the growth increments and growth patterns were very similar.

The heights of the thoracic vertebrae in the first group (Table IV), part of the scoliotic curve, were slightly less than that of the normal thoracic vertebrae of the second group (Table II). No differences could be demonstrated in the growth increments (Fig. 7; compare with Fig. 4). And although a difference between individual thoracic vertebral bodies was observed (Fig. 5B), no sex difference was found.

\section{DISCUSSION}

In the present study the growth increments of thoracic and lumbar vertebrae were determined in children between the ages of 10 and 17 years using standardised full-length anteroposterior spinal radiographs. Measurements were made in only two dimensions and not on lateral radiographs. Lateral views may be of significance in the study of the growth of vertebrae within the
Table III. Lumbar vertebrae from the scoliotic segment (second series)

\begin{tabular}{|c|c|c|c|c|}
\hline \multicolumn{5}{|c|}{ GIRLS } \\
\hline & \multicolumn{2}{|c|}{ Height ( $\mathrm{mm}$ ) } & \multicolumn{2}{|c|}{ Width ( $m m$ ) } \\
\hline & 10 years & 17 years & 10 years & 17 years \\
\hline LI & 21.4 & 29.8 & 35.1 & 39.2 \\
\hline $\mathbf{L} 2$ & 21.5 & 30.4 & 35.1 & 39.5 \\
\hline L3 & 21.7 & 32.3 & 37.0 & 41.2 \\
\hline L4 & 21.4 & 30.1 & 38.8 & 43.0 \\
\hline
\end{tabular}

Table IV. Thoracic vertebrae from the scoliotic segment (first series)

\begin{tabular}{|c|c|c|c|c|}
\hline \multicolumn{3}{|c|}{ BOYS } & \multicolumn{2}{|l|}{ GIRLS } \\
\hline & \multicolumn{2}{|c|}{ Height (mm) } & \multicolumn{2}{|c|}{ Height ( $\mathrm{mm}$ ) } \\
\hline & 10 years & 17 years & 10 years & 17 years \\
\hline T6 & 13.2 & 18.9 & 13.5 & 18.7 \\
\hline $\mathrm{T7}$ & 13.7 & 19.0 & 13.7 & 18.6 \\
\hline $\mathrm{T} 8$ & 13.4 & 18.3 & 14.5 & 19.0 \\
\hline TII & 16.5 & 23.8 & 17.2 & 24.3 \\
\hline
\end{tabular}

scoliotic segment since, according to Dickson et al. (1984), there is an increase in anterior vertebral height at the apex of the curve. The measuring method employed by us determined the maximum height of a vertebral body in an anteroposterior view, as clearly demonstrated in Figure 1.

The first series consisted of 20 children ( 10 girls and 10 boys) with a single thoracic adolescent idiopathic scoliosis between T5-6 and T11-12. The second series consisted of 10 girls with a single lumbar adolescent idiopathic scoliosis. The lumbar vertebrae of the first series and the thoracic vertebrae of the second series can be assumed to show normal growth. The lumbar vertebral bodies showed a greater increase in height than the thoracic vertebral bodies. In boys, L3 and L4 contribute more to the height than L1 and L2. In girls, 


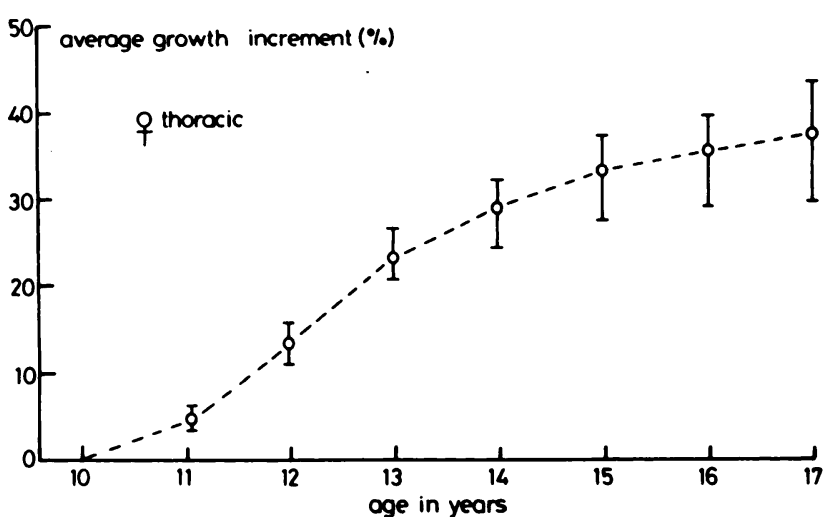

Fig. 4

Average growth increments in height of the thoracic (normal) vertebrae for the second series.

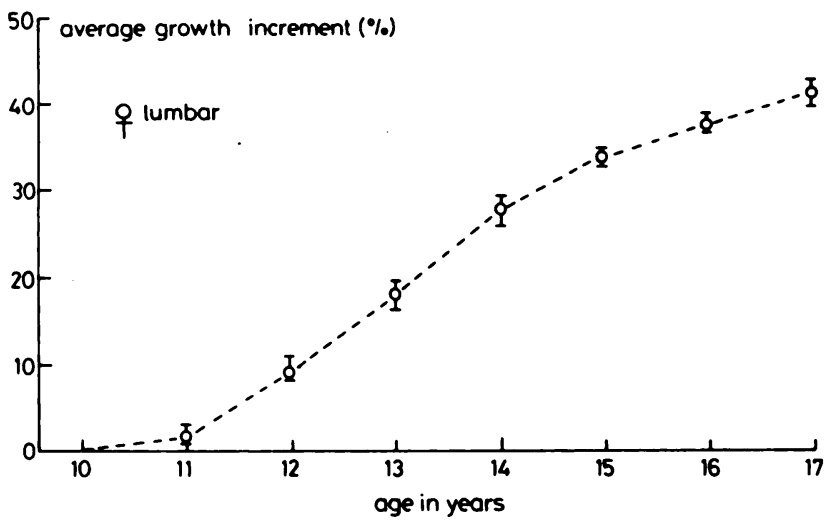

Fig. 6

Average growth increments in height of the lumbar (scoliotic) vertebrae for the second series.

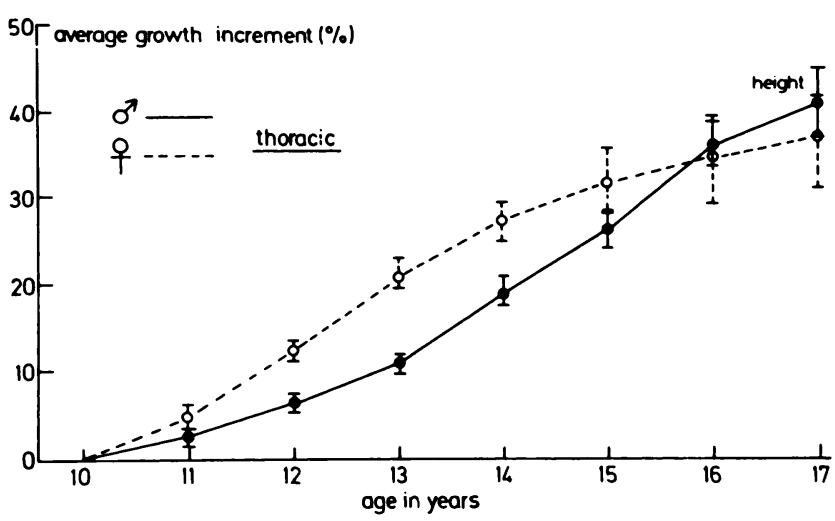

Fig. 7

Average growth increments in height of the thoracic (scoliotic) vertebrae for the first series.

this is true only for L3. These findings correspond with those of Nehme et al. (1980), whose study was based on normal children. Furthermore, the same growth patterns were established. Nehme et al. reported that in normal girls of 10 years of age, the total of the heights of the
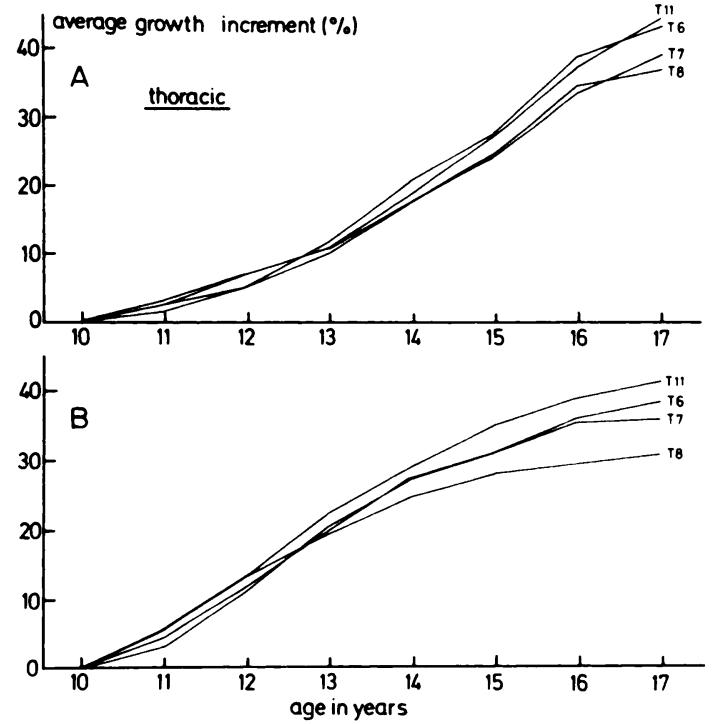

Fig. 5

$\mathrm{T} 7$ and $\mathrm{T} 8$ show less longitudinal growth than $\mathrm{T} 6$ and $\mathrm{T} 11$ in both series. A-normal vertebrae (second series); B-scoliotic vertebrae (first series).

lumbar vertebral bodies was $103.9 \mathrm{~mm}$. In our study this total height for the same age group was $101.4 \mathrm{~mm}$. This difference is not significant.

This shows that we were measuring comparable groups and therefore the assumption that vertebrae outside the scoliotic segment show normal growth appears to be justified. The growth increments of lumbar and thoracic vertebral bodies, respectively showed no significant differences between the first and second series and, in addition, the growth pattern in the scoliotic segment did not differ from that in the normal part of the spine, although the growth of individual vertebral bodies was subject to variation.

Skogland and Miller (1981) found in their study that during growth in early adolescence a greater increase in the height of a mid-thoracic vertebral body could be expected than in a lumbar vertebra. Their study is not comparable to ours, because they did not select their patients according to the type of curve and the age.

The aetiology of idiopathic scoliosis is probably multifactorial and one of the possible factors may be mechanical instability. If so, spinal length and the dimensions of the vertebral bodies and discs may be relevant. It has been suggested that girls have more slender spines and therefore may be more subject to scoliosis. This concept is supported by Skogland and Miller (1981), who found an increased slenderness index for scoliotics in all the groups studied, although in girls of 14 years of age the differences between the scoliotics and controls was too small to be statistically significant $(0.63$ and 0.62 respectively). In boys of 13 years of age they found height/width indices for L4 of 0.54 and 0.51 for scoliotics and controls, respectively. 
A. G. VELDHUIZEN, P. BAAS, P. J. WEBB

Table V. Height/width index in normal lumbar vertebrae (first series)

\begin{tabular}{|c|c|c|c|c|c|c|c|c|c|}
\hline \multicolumn{5}{|c|}{ BOYS } & \multicolumn{5}{|c|}{ GIRLS } \\
\hline Years & Ll & $\mathbf{L 2}$ & $\mathbf{L 3}$ & LA & Years & $\mathbf{L 1}$ & $\mathbf{L 2}$ & $\mathbf{L 3}$ & LA \\
\hline 10 & 0.56 & 0.55 & 0.52 & 0.47 & 10 & 0.59 & 0.60 & 0.58 & 0.54 \\
\hline 11 & 0.56 & 0.55 & 0.52 & 0.48 & 11 & 0.60 & 0.61 & 0.59 & 0.55 \\
\hline 12 & 0.56 & 0.56 & 0.54 & 0.49 & 12 & 0.64 & 0.65 & 0.63 & 0.58 \\
\hline 13 & 0.58 & 0.57 & 0.55 & 0.51 & 13 & 0.67 & 0.68 & 0.68 & 0.62 \\
\hline 14 & 0.59 & 0.58 & 0.57 & 0.53 & 14 & 0.70 & 0.70 & 0.71 & 0.64 \\
\hline 15 & 0.62 & 0.60 & 0.59 & 0.56 & 15 & 0.72 & 0.72 & 0.73 & 0.66 \\
\hline 16 & 0.67 & 0.66 & 0.64 & 0.60 & 16 & 0.75 & 0.75 & 0.76 & 0.67 \\
\hline 17 & 0.70 & 0.69 & 0.67 & 0.61 & 17 & 0.75 & 0.76 & 0.77 & 0.69 \\
\hline
\end{tabular}

The slenderness index in the boys in our series is comparable to that found by Skogland and Miller in their controls. The index for girls of 14 years of age in our groups is 0.63 for the L4 vertebra within the curve and 0.64 when the vertebra was not part of the deformed segment. There is a difference in slenderness between boys and girls (Tables V and VI), but it is questionable if a difference exists between scoliotic and normal spines.

Our study shows that the increase in the height of vertebral bodies involved in the scoliotic region is much the same as that of the remaining vertebrae, and is similar to growth increments reported in the literature. Therefore, in scoliosis a normal length of spinal column may be expected. However, Nordwall and Willner (1975), Burwell, Dangerfield and Vernon (1977) and Leong et al. (1977) have all reported a greater stature among idiopathic scoliotic patients than in healthy controls.

Nordwall and Willner (1975) have demonstrated a significant difference in sitting height after correcting for the loss of height due to scoliosis (Bjure, Grimby and Nachemson 1968). Sitting height is not a reliable indicator of spinal length. It represents of course the sum of the height of the pelvis, spine and cranium: the pelvic height alone accounts for about $18 \%$ of the sitting height and as much as $22 \%$ of the increase in sitting height in girls between 8 and 18 years of age (Anderson, Hwang and Green 1965). The spine only contributes approximately $60 \%$ to the sitting height and it is difficult to contemplate how detailed information concerning spinal dimensions can be obtained from these measurements.

The findings of Willner and others are contradicted by the study of Skogland and Miller (1981) who used direct measurements of the length of the thoracolumbar spine on standardised radiographs. They found no significant differences in length between idiopathic scoliotic patients and controls. Our findings confirmed this and also showed a normal growth potential for each individual vertebra within a scoliotic curve. We could demonstrate no significant difference in the growth increments and spinal dimensions of vertebral bodies involved in the scoliotic curve compared with the rest of the vertebral column.
Table VI Height/width index in the scoliotic segments (second series)

\begin{tabular}{|c|c|c|c|c|}
\hline \multicolumn{5}{|c|}{ GIRLS } \\
\hline Years & $\mathbf{L 1}$ & L2 & $\mathbf{L 3}$ & LA \\
\hline 10 & 0.60 & 0.61 & 0.58 & 0.55 \\
\hline 11 & 0.61 & 0.62 & 0.59 & 0.56 \\
\hline 12 & 0.63 & 0.64 & 0.62 & 0.59 \\
\hline 13 & 0.66 & 0.67 & 0.69 & 0.61 \\
\hline 14 & 0.71 & 0.70 & 0.72 & 0.63 \\
\hline 15 & 0.73 & 0.73 & 0.75 & 0.66 \\
\hline 16 & 0.75 & 0.75 & 0.76 & 0.68 \\
\hline 17 & 0.75 & 0.76 & 0.78 & 0.70 \\
\hline
\end{tabular}

\section{REFERENCES}

Anderson M, Hwang S-C,Green WT. Growth of the normal trunk in boys and girls during the second decade of life: related to age maturity and ossification of iliac epiphysis. J Bone Joint Surg [Am] $1965 ; 47-\mathrm{A}: 1554-64$.

Bjure J, Grimby G, Nachemson A. Correction of body height in predicting spirometric values in scoliotic patients. Scand J Clin Lab Invest 1968;21:191-2.

Burwell RG, Dangerfield PH, Vernon CL. Anthropometry and scoliosis. In: Zorab PA, ed. Scoliosis: proceedings of the fifth symposium held at the Cardiothoracic Institute, Brompton Hospital, London on 21 and 22 September 1976. London: Academic Press, 1977:123-63.

Collis DK, Ponseti IV. Long-term follow-up of patients with idiopathic scoliosis not treated surgically. J Bone Joint Surg [Am] $1969 ; 51-A: 425-45$

Dickson RA, Lawton JO, Archer IA, Butt WP. The pathogenesis of idiopathic scoliosis: biplanar spinal asymmetry. J Bone Joint Surg [Br] $1984 ; 66-\mathrm{B}: 8-15$

Duthie RB. The significance of growth in orthopaedic surgery. Clin Orthop 1959;14:7-19.

Duval-Beaupere G, Dubousset J, Queneau P et al. Pour une théorie unique de l'èvolution des scolioses. Presse Med 1970;78:1141-6.

Leong JCY, Low WD, Mok CK, Yau ACMC. Preliminary report of linear growth in Southern Chinese female patients with adolescent idiopathic scoliosis. J West Pac Orthop Assoc 1977;14:107-8.

Nehme A-ME, Riseborough EJ, Reed RB. Normal spine growth. In: Zorab PA, Siegler D, eds. Scoliosis 1979. London etc: Academic Press, 1980;103-9.

Nordwall A, Willner S. A study of skeletal age and height in girls with idiopathic scoliosis. Clin Orthop 1975;110:6-10.

Skogland LB, Miller JAA. The length and proportions of the thoracolumbar spine in children with idiopathic scoliosis. Acta Orthop Scand 1981;52:177-85.

Willner S. Factors contributing to structural scoliosis. Lund: Studentlitteratur, 1972. 